\title{
Facile Synthesis and Characterization of Tetraaniline Nanostructures via Self-Assembly Method
}

\author{
Y. PAVAN KUMAR ${ }^{1}$, A.V. RAMESH ${ }^{1}$,B.LAVAKUSHA ${ }^{1}$, B. SATISH MOHAN ${ }^{1}$, \\ NEWAY BELACHEW ${ }^{1}$, D. RAMADEVI ${ }^{2}$ and K. BASAVAIAH ${ }^{1 *}$
}

${ }^{1}$ Department of Inorganic and Analytical Chemistry, Andhra University, Visakhapatnam-530003, India

${ }^{2}$ A.U. College of Pharmacuitical Sciences, Andhra University, Visakhapatnam-530003, India

klbasu@gmail.com

Received 1 June 2016 / Accepted 26 June 2016

\begin{abstract}
Tetraaniline (TPANI) nanostructures have been synthesized by using ammonium persulphate as oxidant via in situ chemical oxidative polymerization monomer in presence of organic carboxylic acid. The organic carboxylic acid can act as both dopant as well as surfactant for synthesis of TPANI nanostructures. The resulting TPANI nanostructures have been characterized by x-ray diffraction, UV-Visible spectroscopy, Fourier transform infrared spectroscopy, scanning electron microscopy and transmission electron microscopy. Spectroscopic results indicated formation of TPANI nanostructures. The morphology of TPANI was found to be dependent on the molar ratios of monomer to organic carboxylic acid.
\end{abstract}

Keywords: Intrinsic conducting polymer, Polyaniline, Tetraaniline, Nanostructures, Self-assembly

\section{Introduction}

Over the past decade intrinsic conducting polymer nanostructures have attracted attention due to their potential applications in photovoltaic cells, field effect transistors, light emitting diodes, electrochemical devices, chemical and biological sensor ${ }^{1-5}$. Among intrinsic conducting polymers, polyaniline (PANI) is considered as one of the most promising materials due to its relatively facile synthesis, high electrical conductivity, unique proton dopability, low cost, redox recyclability, good chemical and environmental stability ${ }^{6}$ and potential technological applications such as molecular electronics, light emitting diodes, sensors, actuators, solar cells, light weight batteries and antistatic and anticorrosion coatings ${ }^{7}$.

More recently, nanostructured PANI with different morphology including nanotubes, nanorods, nanofibers and nanowires have received great attention over its bulk counterpart due to their high surface-to-volume ratio and low dimensionality. PANI nanostructures have 
been widely prepared by many research groups varying the synthetic methods such as emulsion polymerization, interfacial polymerization, plasma polymerization, enzymatic polymerization, self-assembly, electrospinning and rapid mixing polymerization in the presence of specific structure directing materials such as zeolite channels, porous membranes, surfactants, polymers and bulky organic acid dopants ${ }^{8-10}$. However, the softtemplate method using structure directing agents in the form of surfactants and bulky organic acids has the advantage in preparing large quantities of PANI nanostructures over hard-template method due to it is very difficult to retain ordered PANI nanostructures as harsh experimental conditions are required for the removal of hard templates ${ }^{11}$. In soft template technique, the external dopant bulky organic acid forms complex with monomer via the acid-base chemistry and, as a formed complex, acts as a soft template for the growth of the TPANI nanostructures.

The oligomers of PANI such as tetraaniline, octaaniline and hexadecaaniline etc., have been investigated theoretically and experimentally as model system for PANI due to their solubility in common solvents, well-defined structure, designed end group and monodispersed molecular weight and similar electrical and chemical properties that of PANI. Despite these advantages of oligomers of PANI, a very little emphasis is given on the synthesis of the nanostructures of PANI oligomers. Among the PANI oligomers, tetraaniline (TANI) has received great attention because it is soluble in common solvents and exhibits similar electroactivity as PANI. The most useful form of PANI is emeraldine (EBPANI), which has ca. 50\% amine and ca. 50\% imine nitrogen, in which one of its four rings is quinoid, the remaining three being benzenoid. TANI is a perfect model compound for PANI.

In this paper, we have reported a simple and straight forward synthesis of TPANI nanostructures by in situ self-assembled method in presence of benzene tetracarboxylic acid (BTCA) as a dopant as well as structure directing agent for formation of TPANI nanostructures. The effect of molar ratio of monomer to BTCA on the morphology was investigated.

\section{Experimental}

$N$-Phenyl-1, 4-phenylediamine (NPPD), ammonium persulphate [APS, $\left.\left(\mathrm{NH}_{4}\right)_{2} \mathrm{~S}_{2} \mathrm{O}_{8}\right)$ ] and benzene tetracarboxylic acid (BTCA) were purchased from Sigma Aldrich and used as received without any further purification. All chemicals are of analytical grade. All the required solutions were prepared using Milli-Q water with resistance greater than $18 \mathrm{M} \Omega$ was obtained from a Millipore Milli-Q system.

\section{Synthesis}

In a typical experimental procedure, $0.02 \mathrm{M}$ solutions of NPPD and $0.02 \mathrm{M}$ BTCA were dissolved individually in $10 \mathrm{~mL}$ of Milli-Q water and then both the solutions were mixed together in a $150 \mathrm{~mL}$ round bottomed flask with constant stirring for an hour at room temperature. Then the reaction mixture was allowed to cool to $0-5^{\circ} \mathrm{C}$ by using an ice-water bath. Then, a pre-cooled solution of $0.02 \mathrm{M}$ aqueous ammonium persulphate was added drop wise to the above under vigorous stirring. Over the course of the reaction, the colour of the reaction mixture slowly turns from a colourless to light blue and eventually to dark green which indicate the formation of BTCA doped TPANI. The reaction was allowed to proceed for $24 \mathrm{~h}$ at $0-5{ }^{\circ} \mathrm{C}$ before allowing it to attain room temperature to yield BTCA doped TPANI. The final product was centrifuged and washed several times with water and methanol and then dried under vacuum at a room temperature for $12 \mathrm{~h}$. The same method has been adopted for preparation of all BTCA doped TPANI, except for varying the molar ratio of NPPD to BTCA from 1:1 to 1:5 for samples 1 to 5 respectively. 


\section{Characterization}

Phase indication of these samples was done by x-ray diffractometer (Siemens AXS D5005 $\mathrm{x}$-ray diffractometer with $\mathrm{Cu}-\mathrm{K} \alpha$ radiation). Morphology was investigated by scanning electron microscope, Transmission electron microscopy (TEM, FEI Tecnai G2 S-Twin with accelerating voltage $200 \mathrm{kV}$ ). FTIR spectra were recorded over the range of $400-4000 \mathrm{~cm}^{-1}$ using a Perkin Elmer SPECTRUM 1000 FTIR Spectrometer to characterize the chemical structure of polymer. The powder samples were mixed thoroughly with potassium bromide $(\mathrm{KBr})$ and pressed into transparent pellets. For UV-Visible absorption spectra the samples were dissolved in dimethylsulphoxide (DMSO) and spectra were recorded on a Shimadzu UV-Vis spectrophotometer, UV-2600. Thermogravimetic analysis was carried out using TGA, Cahn TG131 system with a heating rate of $20^{\circ} \mathrm{C}$ per minute under $\mathrm{N}_{2}$ atmosphere.

\section{Results and Discussion}

The polymerization was performed in aqueous solutions containing NPPD, dopant acid BTCA and ammonium peroxydisulfate (APS). Synthesis of TPANI nanostructures is based on in situ chemical oxidative polymerization of NPPD in an acidic environment with ammonium persulphate as an oxidant in the presence of BTCA. The dopant acid, BTCA acts as softtemplate due to its hydrophilic group (-COOH) and hydrophobic group, BTCA easily forms micelles in an aqueous solution and this act as surfactant also. With progressive polymerization, growth of tube is controlled by elongation process. The presence of excess BTCA prevents the formation of larger particles via steric hindrance and thereby producing TPANI nanostructures.

The absorption spectra of TPANI prepared at different molar ratios of NPPD to BTCA are presented in Figure 1, which are in complete agreement with spectra previously reported in literature ${ }^{12}$. The absorption spectra show three bands at 278, 343 and $625 \mathrm{~nm}$. Absorption peaks at 343 and $625 \mathrm{~nm}$ were assigned to $\pi \rightarrow \pi *$ transition of benzenoid rings in the TPANI chain and the transition caused by inter chain charge transfer from two adjacent benzenoid ring to the quinoid ring of TPANI chain respectively. Sharp peak at $278 \mathrm{~nm}$ ascribed to the $\pi \rightarrow \pi *$ transition in the benzenoid rings of PSS confirms the presence of PSS in the nanocomposites.

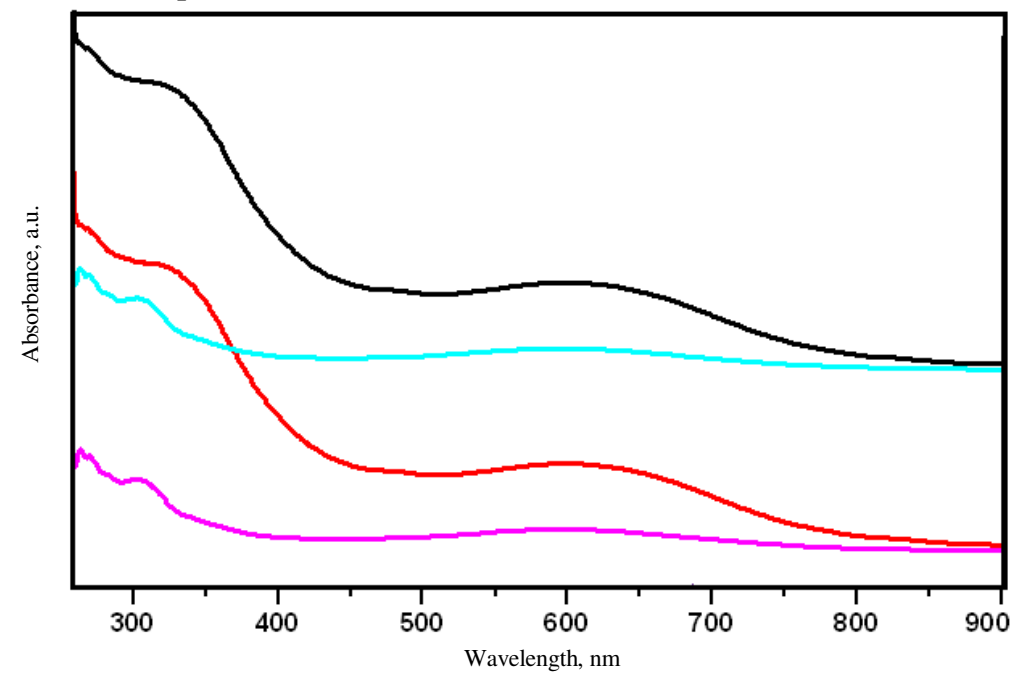

Figure 1. UV-Visible spectra of TPANI prepared at different molar ratios of NPPD to BTCA 
FTIR spectra of TPANI prepared at different molar ratios of NPPD to BTCA were depicted in Figure 2. All the peaks were in good agreement with those reported in literature ${ }^{13-15}$. The bands at 3160,1590 and $1493 \mathrm{~cm}^{-1}$ were assigned to $\mathrm{N}-\mathrm{H}$ stretching vibration, $\mathrm{C}=\mathrm{C}$ stretching of quinoid phenyl and benzenoid phenyl rings, respectively. The band at $1398 \mathrm{~cm}^{-1}$ was due to stretching frequency of $\mathrm{B}-\mathrm{N}=\mathrm{Q}$ moiety (B refers to benzenoid and $\mathrm{Q}$ refers to quinoid ring). The presence of this peak confirms that the TPANI is doped with BTCA. The band at $1301 \mathrm{~cm}^{-1}$ was assigned to $\mathrm{C}-\mathrm{N}$ stretching vibrations of the 1, 4- disubstituted benzene ring of TPANI.

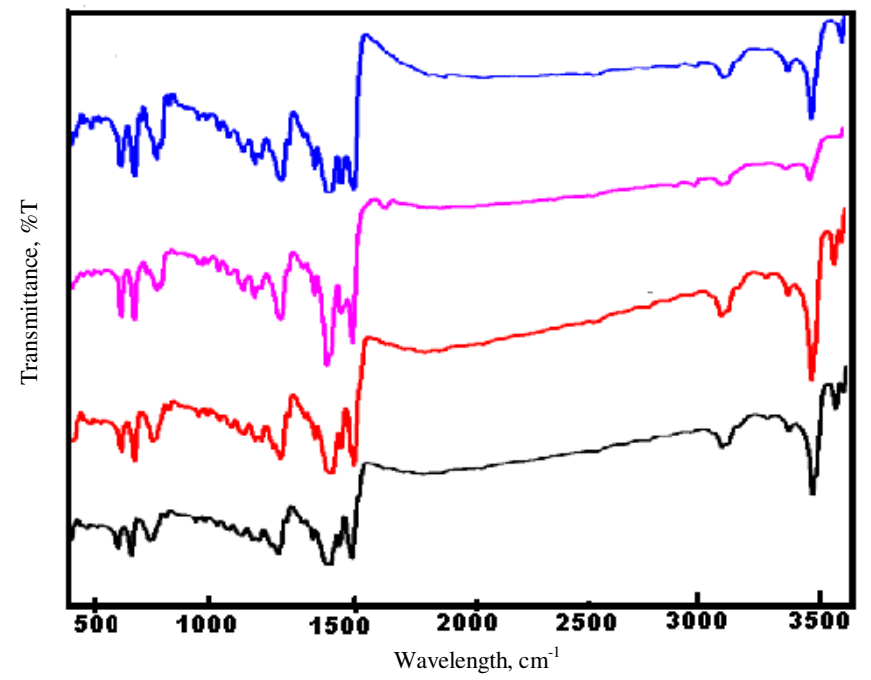

Figure 2. FTIR spectra of TPANI prepared at different molar ratios of NPPD to BTCA

BTCA doped TPANI nanostructures were prepared at five different molar ratios of BTCA to NPPD prepared in a large quantity by chemical oxidation of NPPD using APS as an oxidant in the presence of BTCA. In order to investigate the effect of the concentration of the NPPD to dopant acid on the morphology of the obtained TPANI, SEM images were carried out in detail.

SEM images of TPANI prepared with different molar ratios NPPD to BTCA were presented in Figure 3 SEM image of TPANI prepared with 1:5 molar ratio of NPPD to BTCA is depicted in Figure 3(d) shows nanorod like morphology. Morphology for other TPANI prepared with molar ratios of NPPD to BTCA equal to 1:1, 1:3 and 1:4 were presented in Figure 3(a-c) which do not show formation of tubes. Hence, morphology of composites seems to be critically dependent on molar ratio of NPPD to BTCA.
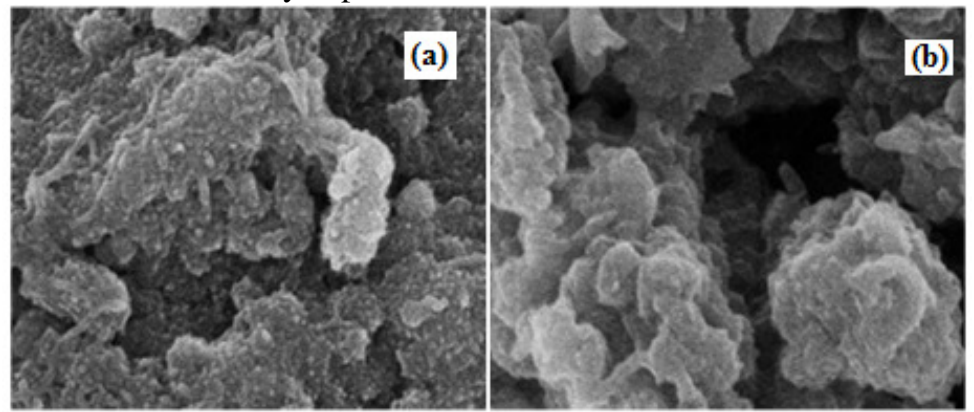


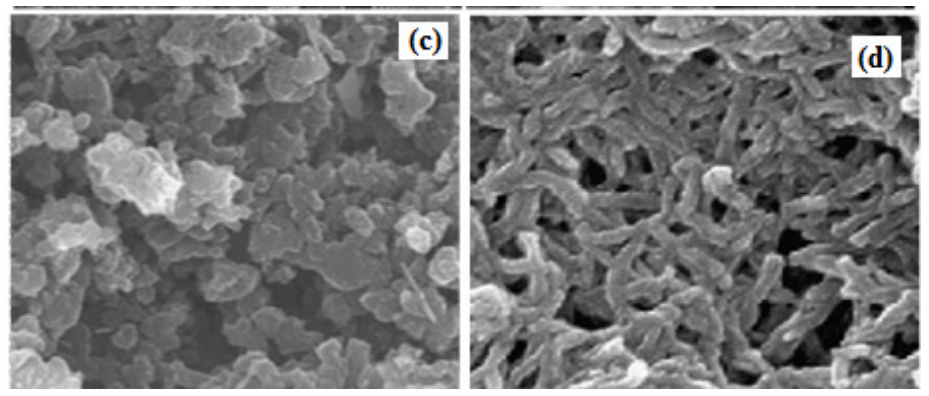

Figure 3. SEM images of BTCA doped TPANI prepared at (a) 1:1, (b) 1:3, (c) 1:4 and (d) 1:5 molar ratios of NPPD to BTCA

Transmission electron microscopy (TEM) image of TPANI prepared at 1:5 molar ratio of NPPD to BTCA is displayed in Figure 4, shows TPANI rods like structure with diameter of 15-25 and length of few hundred nanometres.

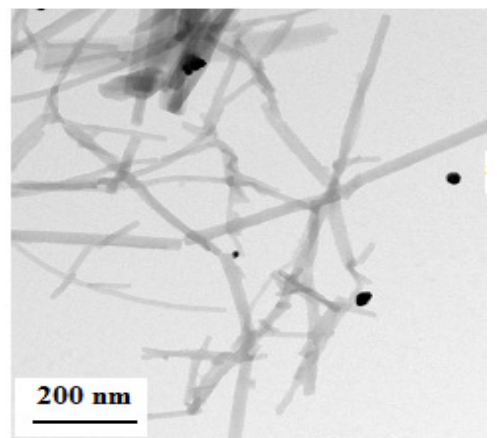

Figure 4. Transmission electron microscopy image of TPANI prepared at 1:5 molar ratio of NPPD to BTCA

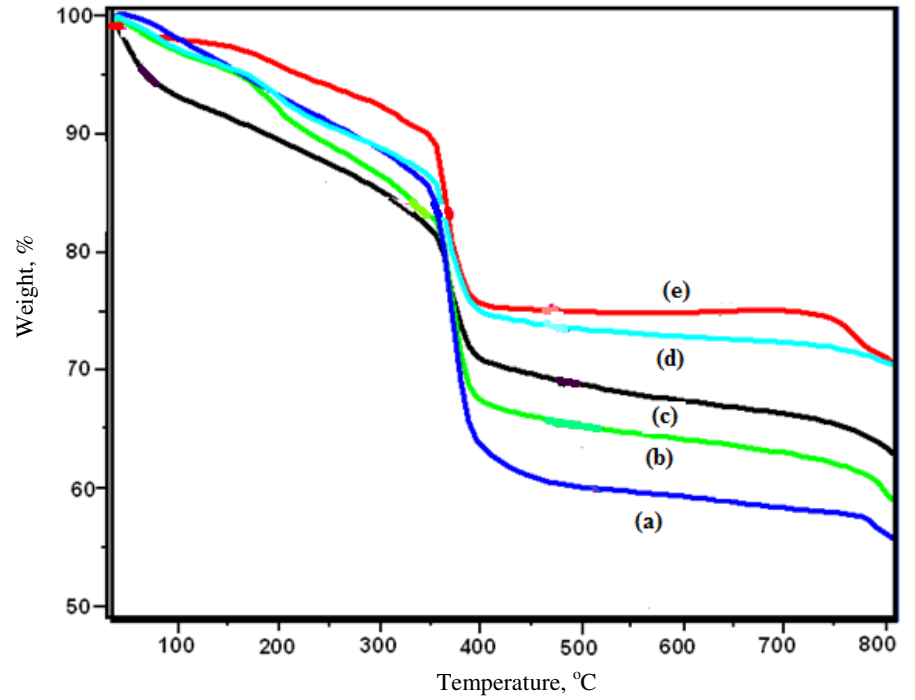

Figure 5. TGA of TPANI prepared at (a) 1:1, (b) 1:2, (c) 1:3, (d) 1:4 and (e) 1:5 molar ratios of NPPD to BTCA 
Thermal behaviour of TPANI was investigated by thermogravimetric analysis (TGA). As shown in Figure 5, the composite exhibit three steps of weight losses. TG curve shows a continuous weight loss up to $275^{\circ} \mathrm{C}$ is ascribed to the removal of water, excess of unbound BTCA and other volatiles in composites. Weight loss in temperature range of $275-500{ }^{\circ} \mathrm{C}$, is due to the degradation of the bound BTCA and decomposition of TPANI itself. In the third weight loss region is $\left(500-840{ }^{\circ} \mathrm{C}\right)$ due to decomposition of TPANI chain.

\section{Conclusion}

In conclusion, we have demonstrated a simple, reproducible and in-situ self-assembly process for synthesis of BTCA doped TPANI using APS as an oxidant in the presence of BTCA. SEM and TEM results revealed that PANI tubes like morphology. Morphology of TPANI is critically dependent on the molar ratios of NPPD to BTCA. Spectroscopic results clearly shows the successfully formation of TPANI. TGA results indicated that dopant BTCA enhanced the thermal stability of TPANI.

\section{References}

1. MacDiarmid A G, Rev Mod Phys., 2001, 73(3), 701-712;

DOI:10.1103/RevModPhys.73.701

2. Kumar D and Sharma R C, Eur Polym J., 1998, 34(8), 1053-1060; DOI:10.1016/S0014-3057(97)00204-8

3. Janata J and Josowicz M, Nat Mater., 2003, 2, 19-24; DOI:10.1038/nmat768

4. Tseng R J, Huang J, Ouyang J, Kaner R B and Yang Y, Nano Lett., 2005, 5(6), 1077 1080; DOI:10.1021/n10505871

5. Rahman M A, Kumar P, Park D S and Shim Y B, Sensors, 2008, 8(1), 118-141; DOI: $10.3390 / \mathrm{s} 8010118$

6. Chan H S , Ng S C, Sim W S, Seow S H, Tan K L and Tan B T, Macromolecules, 1993, 26(1), 144-150; DOI:10.1021/ma00053a022

7. Sfez R, De-Zhong L, Turyan I, Mandler D and Yitzchaik S, Langmuir, 2001, 17(9), 2556-2559; DOI:10.1021/la001343d

8. Choi J, Kim S J, Lee J, Lim J H, Lee S C and Kim K J, Electrochem Commun., 2007, 9, 971-975; DOI:10.1016/j.elecom.2006.11.038

9. Chen J, Chao D, Lu X and Zhang W, Mater Lett., 2007, 61(6), 1419-1423; DOI:10.1016/j.matlet.2006.07.043

10. Huang J X and Kaner R B, Angew Chem Int Ed., 2004, 43(43), 5817-5821; DOI:10.1002/anie.200460616

11. Chiou N R, Lee L J and Epstein A J, J Mater Chem., 2008, 18, 2085-2089; DOI:10.1039/B719320C

12. Hasik M, Kurkowska I and Bernasik A, React Funct Polym., 2006, 66(12), 17031710; DOI:10.1016/j.reactfunctpolym.2006.07.004

13. Chen S A and Lee H T, Macromolecules, 1993, 26, 3254-3261;

DOI:10.1021/ma00065a002

14. Trhcova M, Stejskal J and Prokes J, Synth Met., 1999, 101(1-3), 840-841; DOI:10.1016/S0379-6779(98)01310-1

15. Neoh K G, Pun M Y, Kang E T and Tan K L, Synth Met., 1995, 73(3), 209-215; DOI:10.1016/0379-6779(95)80018-2

16. Kim B J, Oh S G, Han M G and Im S S, Langmuir, 2000, 16(14), 5841-5845; DOI:10.1021/la9915320 